\title{
THE INFLUENCE OF NEONATAL EXPOSURE TO THIMEROSAL CONTAINING VACCINES ON INFANTS DEVELOPMENT IN THE FIRST YEARS OF LIFE
}

\author{
D. Mrozek-Budzyn, R. Majewska, A. Kieltyka, M. Augustyniak, E. Mroz, A. Skarupa
}

Chair of Epidemiology and Preventive Medicine, Jagiellonian University Medical College, Krakow, Poland

Background and aims: The controversial topic of the early human exposure to mercury is ethylmercury, which is present in the thimerosal-containing vaccines (TCV). The objective of this analysis was to determine the relationship between the neonatal exposure to TCV and cognitive and psychomotor development of children during the first 2 years of life.

Methods: The cohort recruited prenatally in Krakow, Poland, included 310 children vaccinated in neonatal period against hepatitis-B using formula with or without thimerosal. The children development was assessed using the Fagan test $\left(6^{\text {th }}\right.$ month of life), and the Bayley Scales of Infant Development BSID-II $\left(12^{\text {th }}\right.$ and $24^{\text {th }}$ month). Results were determined by multivariable linear and logistic regression, adjusted to potential confounders.

Results: Children exposed to TCV in neonatal period had significantly lower psychomotor BSID-II scores at $12^{\text {th }}$ and $24^{\text {th }}$ month of life than those vaccinated with no TCV $(\beta=-3.7, p=0.046 ; \beta=-6.7, p<0.001$, respectively). The risk of the delayed psychomotor development was about twofold higher in TCV vaccinated group, however, it was not statistically significant. Results of the Fagan administered at $6^{\text {th }}$ month and BSID-II mental developmental tests were not associated with the TCV-related exposure.

Conclusions: Our study demonstrated that TCV administration in neonatal period was associated with significantly lower infants' psychomotor scores during first two years of life. However, TCV did not have an impact on children's cognitive development.

All studied children were a sample from cohort study on the susceptibility of fetus and child to environmental factors followed in Krakow with Columbia University. 